\title{
What is the Optimal Method Assessing for Persistent Villous Atrophy in Adult Coeliac Disease?
}

\author{
Sarah Helen Coleman ${ }^{1}$, Anupam Rej ${ }^{1}$, Elisabeth Megan Rose Baggus ${ }^{1}$, Michelle S. Lau ${ }^{1}$, Lauren J Marks ${ }^{1}$, Marios \\ Hadjivassiliou ${ }^{1}$, Simon S. Cross ${ }^{2}$, Daniel A. Leffler ${ }^{3}$, Luca Elli ${ }^{4}$, David Surendran Sanders ${ }^{1}$
}

1) Academic Department

of Gastroenterology, Royal Hallamshire Hospital, Sheffield Teaching Hospitals, Sheffield, United Kingdom;

2) Academic Unit of Pathology, Department of Neuroscience, University of Sheffield, Sheffield, United Kingdom;

3) Celiac Center and Division of Gastroenterology, Beth Israel Deaconess Medical Center, Boston, Massachusetts, USA;

4) Center for Prevention and Diagnosis of Celiac Disease, Division of Gastroenterology and Endoscopy, Fondazione IRCCS Ca' Granda Ospedale Maggiore Policlinico, Milano, Italy

Address for correspondence: Sarah H Coleman, Medical Student,

University of Sheffield, shcoleman1@sheffield.ac.uk

Received: 05.01.2021 Accepted: 30.03.2021

\section{ABSTRACT}

Background \& Aims: Methods of assessing gluten-free diet (GFD) adherence in adults with coeliac disease (CD) include serological testing, dietitian evaluation, questionnaires and repeat duodenal biopsies. Persisting villous atrophy (VA) is associated with CD complications, however gastroscopy with biopsies is expensive and invasive. This study aimed to assess the abilities of a duodenal bulb (D1) biopsy and the Celiac Dietary Adherence Test (CDAT) to detect persisting VA in adults with CD.

Methods: A prospective observational study of adult CD patients referred for follow-up duodenal biopsies was performed. Quadrantic biopsies were taken from the second part of the duodenum (D2), in addition to a D1 biopsy. Patients underwent follow-up serological testing, and completed the CDAT and Biagi Score. These non-invasive adherence markers were compared against duodenal histology.

Results: 368 patients (mean age 51.0 years, 70.1\% female) had D1 and D2 biopsies taken at follow-up gastroscopy. Compared to D2 biopsies alone, additional D1 biopsies increased detection of VA by $10.4 \%$ $(\mathrm{p}<0.0001) .201$ patients (mean age 50.3 years, 67.7\% female) completed adherence questionnaires and serology. When detecting VA, sensitivities and specificities of these markers were $39.7 \%$ and $94.2 \%$ for IgAtTG, 38.1\% and $96.4 \%$ for IgA-EMA, 55.6\% and 52.2\% for CDAT and $20.6 \%$ and $96.4 \%$ for the Biagi score. Conclusions: Bulbar biopsies increase detection of persisting VA by 10.4\%. Serology, CDAT and Biagi performed poorly when predicting VA. The gold standard for predicting persisting VA remains repeat biopsy.

Key words: coeliac disease - small intestine - compliance/adherence - villous atrophy.

Abbreviations: AOR: adjusted odds ratio; AUC: area under the curve; CD: coeliac disease; CDAT: Coeliac Dietary Adherence Tool; D1: duodenal bulb; D2: second part of the duodenum; EMA: anti-endomysium antibodies GFT: gluten-free diet; NPV: negative predictive value; PPV: positive predictive value; ROC: receiver operating characteristic; tTG: anti-tissue transglutaminase antibodies; USCD: ultra-short coeliac disease; VA: villous atrophy.

\section{INTRODUCTION}

Coeliac disease $(\mathrm{CD})$ is an immune-mediated enteropathy triggered by dietary gluten exposure in genetically susceptible individuals, with a global prevalence of between 0.7 $1.4 \%[1,2]$. Currently the only treatment for $\mathrm{CD}$ is a gluten-free diet (GFD). Lifelong adherence to a GFD is challenging, and CD patients report a high treatment burden [3]. Ultimately, level of GFD adherence achieved results from patients' own evaluation of the benefits against the costs, with rates of strict GFD adherence reported to be between 42 $91 \%$ [4]. The leading cause of non-responsive CD is ongoing gluten exposure [5-7], therefore monitoring GFD adherence is a crucial aspect of the long-term follow-up in CD patients.

Villous atrophy (VA) is the only factor proven to be associated with CD complications, including lymphoproliferative malignancies [8], osteoporosis and fractures $[9,10]$ and nutritional deficiencies $[11,12]$. Therefore repeat duodenal biopsies to assess for disease remission or potential ongoing gluten ingestion may be viewed as the gold standard for assessing treatment outcome; however current guidelines do not mandate follow-up biopsies in CD patients $[1,13,14]$. Repeat gastroscopies with duodenal biopsies are expensive, invasive procedures with poor patient tolerability, which is problematic if patients were required to have many during follow-up $[15,16]$. Further limitations of duodenal biopsies include sampling error as a result of patchy mucosal damage, 
and high interobserver variability between pathologists $[17$, 18]. Rate of mucosal healing after GFD initiation varies between individuals, with reversal of VA occurring in 34$65 \%$ after two years and 66-85.3\% after five years [19-22]. Understanding differential rates of mucosal healing is a vital concept as it helps to define the optimum timing of follow-up biopsy [14].

Due to the limitations of performing repeat duodenal biopsies, many non-invasive methods of assessing adherence have been studied including coeliac serology, dietitian evaluation and validated adherence scores which may be used to optimize the use and timing of repeat biopsy [23]. Studies have reported poor performance of non-invasive adherence markers. Dietitian evaluation is reported to have a sensitivity and specificity of $64 \%$ and $80 \%$ respectively when predicting persisting VA [24]. Coeliac serology has sensitivities and specificities of $44.7-50 \%$ and $83-86.4 \%$ respectively for $\operatorname{IgA}$ anti-tissue transglutaminase antibodies (tTG) and 37.7-45\% and $89.4-91 \%$ respectively for IgA anti-endomysium antibodies (EMA) [25, 26], demonstrating that sole reliance on followup serology fails to detect the majority of CD patients with persisting VA. One validated adherence score devised by Biagi et al. [27], has previously been found to correlate with duodenal histology [27-29] however was recently found to have a lower sensitivity than that of serology, at $24.7 \%$ [26].

When focusing on assessment of GFD adherence, there remain two key unanswered questions. Firstly is the role of the duodenal bulb (D1) biopsy. Bulbar biopsies are vital in diagnosing cases of ultra-short coeliac disease (USCD) [30], and a recent meta-analysis revealed that inclusion of additional D1 biopsies increased the diagnostic rate of adult CD by $8 \%$ (95\%CI 6-10\%) [31]. However, there is a paucity of data pertaining to the role of D1 biopsies in the follow-up of patients with established CD. Only two studies, involving a total of 98 patients, have investigated the benefit of additional D1 biopsies in assessing disease remission [32, 33]. These studies found that between 14.1-15.4\% of patients with established CD had persisting VA confined to the duodenal bulb $[32,33]$ demonstrating the potential increased yield of D1 biopsies to increase the detection of persisting VA.

Secondly, the role of the Coeliac Dietary Adherence Tool (CDAT) [34], the most widely used adherence questionnaire, is undetermined. This questionnaire has been shown to correlate with dietetic evaluation, serology and self-reported adherence $[34,35]$, however it has never been compared against duodenal histology and therefore its ability to predict persisting VA remains unknown.

This study aimed to evaluate the benefit of additional duodenal bulb biopsies in detecting persisting VA in adults with established CD. We also aimed to investigate the ability of the CDAT questionnaire to predict persisting VA.

\section{METHODS}

\section{Study design and patients}

This observational study was carried out at Sheffield Teaching Hospitals (STH) NHS Foundation Trust between March 2013 and December 2019. Patients were primarily prospectively recruited at the time of follow-up biopsies, with additional patients recruited from our database of CD patients. Inclusion criteria included patients aged $\geq 16$ who had already been definitively diagnosed with $\mathrm{CD}$, and had been referred for follow-up duodenal biopsies to confirm disease remission, or to assess persisting symptoms or possibility of refractory CD. Blood samples were taken for follow-up coeliac serology and patients were invited to complete a series of questionnaires. A gastroscopy with duodenal biopsies was also performed on each patient.

\section{Patient questionnaires}

Firstly, patients were invited to complete a general questionnaire about demographic information and symptoms they experienced at the time of their follow-up. Secondly, patients were asked to complete two validated adherence questionnaires, the Biagi adherence score (Fig. 1) and the CDAT (Fig. 2). A member of the research team was available during questionnaire completion.

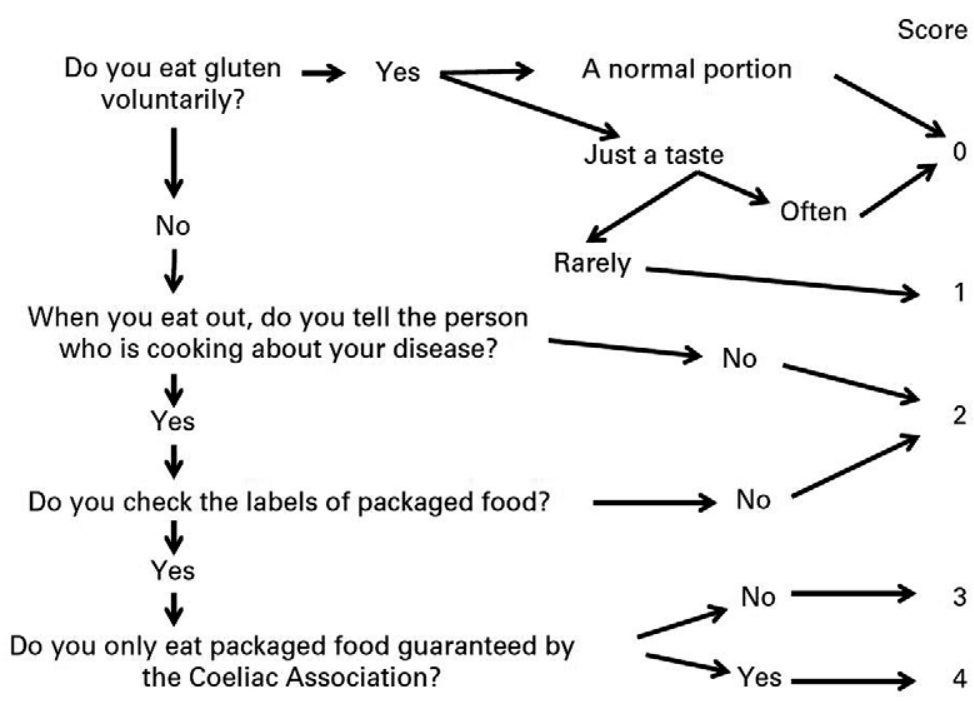

Fig. 1. Adherence score devised by Biagi et al. [27]. The questionnaire produces a final score between 0 and 4 . Scores of 3 or 4 indicating strict GFD adherence, and scores 0-2 signifies inadequate adherence. 


\begin{tabular}{|c|c|c|c|c|c|}
\hline Question & 1 & 2 & 3 & 4 & 5 \\
\hline $\begin{array}{l}\text { Have you been bothered by low energy } \\
\text { level during the past } 4 \text { weeks? }\end{array}$ & $\begin{array}{l}\text { None of the } \\
\text { time }\end{array}$ & A little of the time & $\begin{array}{l}\text { Some of the } \\
\text { time }\end{array}$ & Most of the time & All of the time \\
\hline $\begin{array}{l}\text { Have you been bothered by headaches } \\
\text { during the past } 4 \text { weeks? }\end{array}$ & $\begin{array}{l}\text { None of the } \\
\text { time }\end{array}$ & A little of the time & $\begin{array}{l}\text { Some of the } \\
\text { time }\end{array}$ & Most of the time & All of the time \\
\hline $\begin{array}{l}\text { I am able to follow a GFD when dining } \\
\text { outside my home }\end{array}$ & Strongly agree & Somewhat agree & $\begin{array}{l}\text { Neither agree } \\
\text { nor disagree }\end{array}$ & Somewhat disagree & Strongly disagree \\
\hline $\begin{array}{l}\text { Before I do something I carefully consider } \\
\text { the consequences }\end{array}$ & Strongly agree & Somewhat agree & $\begin{array}{l}\text { Neither agree } \\
\text { nor disagree }\end{array}$ & Somewhat disagree & Strongly disagree \\
\hline I do not consider myself a failure & Strongly agree & Somewhat agree & $\begin{array}{l}\text { Neither agree } \\
\text { nor disagree }\end{array}$ & Somewhat disagree & Strongly disagree \\
\hline $\begin{array}{l}\text { How important to your health are } \\
\text { accidental gluten exposures? }\end{array}$ & Very important & $\begin{array}{l}\text { Somewhat } \\
\text { important }\end{array}$ & Neutral/unsure & A little important & Not at all important \\
\hline $\begin{array}{l}\text { Over the past } 4 \text { weeks, how many times } \\
\text { have you eaten foods containing gluten } \\
\text { on purpose? }\end{array}$ & 0 (never) & $1-2$ & $3-5$ & $6-10$ & $>10$ \\
\hline
\end{tabular}

NOTE. Scores are additive from 7 to 35 , with higher scores denoting worse GFD adherence. A total of $92.2 \%$ of individuals with a combined score of less than $13(n=113$ of 200$)$ showed excellent or very good GFD adherence. A total of $83.3 \%$ of individuals with scores of greater than 17 ( $n=24$ of 200) had fair to poor GFD adherence.

Fig. 2.The CDAT questionnaire devised by Leffler et al. [34]. This is a 7-item questionnaire producing an additive score from 7 to 35, with higher scores signifying worse GFD adherence. A score $<13$ predicts adequate GFD adherence.

\section{Follow-up serology}

IgA-tTG were detected using an automated enzymelinked immunosorbent assay. Prior to 12th December 2014 the AESKULISA assay was used (normal range $=0-15 \mathrm{U} / \mathrm{ml}$ ), thereafter the Thermo Fisher ELISA assay was used (normal range $=0-7 \mathrm{U} / \mathrm{ml}$ ). IgA-EMA testing was performed using immunofluorescence techniques with monkey oesophageal tissue as a substrate. Blood samples for serological testing were interpreted by biochemical scientists in the Northern General Hospital (NGH) Immunology Department.

\section{Follow-up histology}

Four quadrantic biopsy samples were taken from the second part of the duodenum (D2), in addition to a D1 biopsy, as part of standard practice. Histological analysis of biopsy samples took place in the Histopathology Department at RHH. Biopsy samples were fixed in formalin and subsequently embedded in paraffin wax. Sample cross-sections at $4 \mu \mathrm{m}$ thick were stained with haematoxylin-eosin stain to allow visualisation of duodenal mucosa. Samples were viewed and graded by histopathologists according to the modified MarshOberhuber classification [36]. Patients achieving reversal of VA (Marsh grades 0-2) in both D1 and D2 were deemed to have reached 'mucosal recovery', whereas persisting VA was defined as Marsh grades 3a-3c.

\section{Ethical considerations}

Ethics approval was granted by the Yorkshire and the Humber - Sheffield Research Ethics Committee (REC reference: 14/YH/1216).

\section{Statistical analysis}

Descriptive statistics were used to summarise data. Categorical data was summarised by frequencies and percentages, means and standard deviations (SD) were used for normally distributed continuous data, and medians and interquartile ranges (IQR) were used for skewed continuous data. To compare the sensitivity of biopsy sites in detecting persisting VA, a McNemar test for correlated proportions was used. Univariate analysis of demographic and clinical characteristics was performed. One-way analysis of variance (ANOVA) was used for normally distributed continuous variables, Kruskal-Wallis test was used for skewed continuous variables, and Chi-squared test was used for categorical variables. Multivariate analysis correcting for demographic factors and concurrent clinical features was done using binary logistic regression. At the time of data analysis, duration of disease at the time of follow-up was calculated using patients' diagnosis dates, to allow time to mucosal healing to be estimated retrospectively.

Test characteristics of non-invasive adherence markers including Biagi adherence score, CDAT, IgA-EMA and IgA-tTG serology for predicting ongoing VA were then analysed. Correlation between each non-invasive marker and duodenal histology was analysed using Chi-squared tests. Diagnostic accuracies of non-invasive markers were reported as sensitivity, specificity, positive predictive value (PPV), and negative predictive value (NPV) measured against the reference standard of duodenal histology. Receiver operating characteristic (ROC) curves were produced from paired sensitivities and specificities, and the area under the curve (AUC) was reported.

Statistical analyses were performed using IBM SPSS Statistics version 26.

\section{RESULTS}

A total of 368 patients (mean age 51.0 years (SD 16.2), $70.1 \%$ female) had both D1 and D2 follow-up biopsies available. Persisting VA was observed in $33.7 \%(n=124)$ of D1 samples, and $32.6 \%(n=120)$ of D2 samples (Table I). The median period of time of persisting VA in D1 was 5.9 years (IQR 3.1 - 12.0), compared to 6.2 years for persisting VA in D2 (IQR 3.2 - 13.3). Among the patients with persisting VA were 3 patients with complicated $\mathrm{CD}$, all of whom had persisting VA in both D1 and D2. Additional D1 biopsies increased detection of VA by $10.4 \%$ compared to D2 biopsies alone $(\mathrm{p}<0.0001)$. $21.2 \%(n=78)$ of patients had a discrepancy in Marsh grading between D1 and D2, with 50.0\% (39/78) having the most severe lesion in the D1. Specific to VA, rather than variation in total 
Table I. Histological appearance of duodenal bulb (D1) and of the second part of the duodenum (D2) biopsies

\begin{tabular}{|c|c|c|c|c|c|c|c|c|}
\hline & & \multicolumn{6}{|c|}{ D1 Histology } & \multirow[t]{2}{*}{ Total } \\
\hline & & Marsh 0 & Marsh 1 & Marsh 2 & Marsh 3a & Marsh 3b & Marsh 3c & \\
\hline \multirow{6}{*}{$\begin{array}{l}\text { D2 } \\
\text { histology }\end{array}$} & Marsh 0 & 135 & 11 & 1 & 2 & 0 & 0 & 149 \\
\hline & Marsh 1 & 13 & 47 & 0 & 6 & 1 & 1 & 68 \\
\hline & Marsh 2 & 8 & 6 & 13 & 2 & 1 & 1 & 31 \\
\hline & Marsh 3a & 4 & 5 & 0 & 39 & 9 & 0 & 57 \\
\hline & Marsh 3b & 0 & 1 & 0 & 1 & 29 & 4 & 35 \\
\hline & Marsh 3c & 0 & 0 & 0 & 1 & 0 & 27 & 28 \\
\hline Total & & 160 & 70 & 14 & 51 & 40 & 33 & 368 \\
\hline
\end{tabular}

Marsh grade, 15 patients had differing degrees of VA between biopsy sites. Of these patients $86.7 \%(13 / 15)$ had more severe VA in the D1.

Univariate and multivariate analyses of demographic and clinical features according to pattern of persisting VA are displayed in Tables II and III, respectively. Patients without persisting VA appeared younger at follow-up than those with either persisting VA confined to the bulb or more extensive VA $(p=0.034)$, however this was not reproduced on multivariate analysis. The only clinical feature associated with persistent VA pattern was weight loss. On multivariate analysis, patients with more extensive VA had a $2.14(1.18$ - 3.90) times higher odds of weight loss compared to patients without persisting VA $(p=0.01)$. From patients reporting ongoing weight loss $44.6 \%$ had persisting VA, whereas from patients reporting other classical CD symptoms such as diarrhoea and steatorrhoea (floating stools) only $35.3 \%$ and $35.4 \%$ had persisting VA respectively.

At the time of follow-up, the proportion of patients achieving mucosal recovery was relatively consistent in this study. Fig. 3 demonstrates the proportion of patients achieving mucosal recovery in each time category.

In total, 201 patients (mean age 50.3 years, $67.7 \%$ female) completed adherence questionnaires and follow-up serology.

Bar chart displaying proportion of patients achieving mucosal recovery in each time category

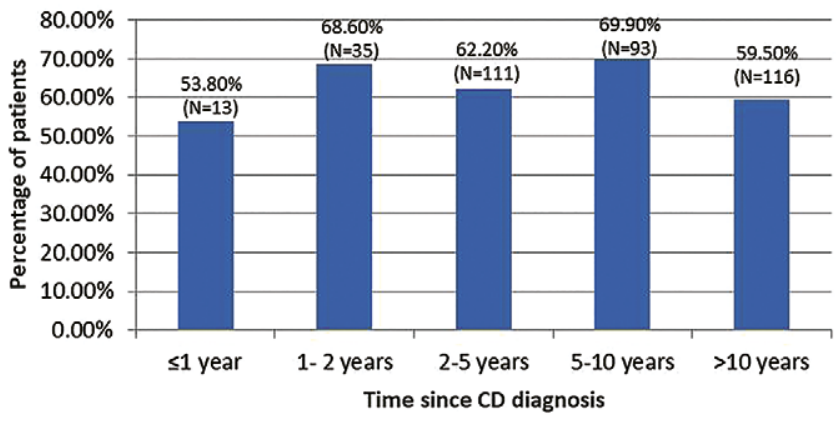

Fig. 3. Graph displaying rates of mucosal recovery against timing of follow-up biopsy.

Table II. Summary of univariate analysis of patient demographics and clinical features by pattern of persisting villous atrophy

\begin{tabular}{|c|c|c|c|c|c|}
\hline & Total $(n=368)$ & $\begin{array}{l}\text { VA confined to } \\
\text { D1 }(n=14)\end{array}$ & $\begin{array}{l}\text { Other patterns of } \\
\text { VA }(n=120)\end{array}$ & $\begin{array}{l}\text { No persisting VA } \\
\qquad(\mathrm{n}=234)\end{array}$ & p-value \\
\hline Mean age (years) at follow-up (SD) & $51.0(16.2)$ & $56.6(16.8)$ & $53.5(15.3)$ & $49.4(16.4)$ & $0.034^{*}$ \\
\hline Female gender, n (\%) & $258(70.1 \%)$ & $7(50.0 \%)$ & $82(68.3 \%)$ & $169(72.2 \%)$ & 0.184 \\
\hline White/Caucasian ethnicity $\mathrm{n} / \mathrm{n}(\%)$ & $303 / 323(93.8 \%)$ & $12 / 12(100.0 \%)$ & $92 / 99(92.9 \%)$ & $199 / 212(93.9 \%)$ & 0.630 \\
\hline Constipation, n (\%) & $44(13.6 \%)$ & $1(8.3 \%)$ & $13(13.1 \%)$ & $30(14.2 \%)$ & 0.837 \\
\hline Diarrhoea, n (\%) & $51(15.8 \%)$ & $2(16.7 \%)$ & $16(16.2 \%)$ & $33(15.6 \%)$ & 0.987 \\
\hline Alternating bowel habit, n (\%) & $54(16.7 \%)$ & $2(16.7 \%)$ & $13(13.1 \%)$ & $39(18.4 \%)$ & 0.511 \\
\hline Flatulence, n (\%) & $139(43.0 \%)$ & $6(50.0 \%)$ & $34(34.3 \%)$ & $99(46.7 \%)$ & 0.108 \\
\hline Bloating, n (\%) & $171(52.9 \%)$ & $7(58.3 \%)$ & $45(45.5 \%)$ & $119(56.1 \%)$ & 0.199 \\
\hline Weight loss, n (\%) & $65(20.1 \%)$ & $1(8.3 \%)$ & $28(28.3 \%)$ & $36(17.0 \%)$ & $0.040^{*}$ \\
\hline Floating stools, n (\%) & $79(24.5 \%)$ & $2(16.7 \%)$ & $26(26.3 \%)$ & $51(24.1 \%)$ & 0.746 \\
\hline Abdominal pain, n (\%) & $21(6.5 \%)$ & $1(8.3 \%)$ & $3(3.0 \%)$ & $17(8.0 \%)$ & 0.243 \\
\hline Reflux/dyspepsia, n (\%) & $12(3.7 \%)$ & $0(0.0 \%)$ & $3(3.0 \%)$ & $9(4.2 \%)$ & $0.848^{\dagger}$ \\
\hline Nausea/vomiting, n (\%) & $14(4.3 \%)$ & $0(0.0 \%)$ & $3(3.0 \%)$ & $11(5.2 \%)$ & $0.744^{\dagger}$ \\
\hline Low energy, n (\%) & $227(70.3 \%)$ & $6(50.0 \%)$ & $66(66.7 \%)$ & $155(73.1 \%)$ & 0.150 \\
\hline Urgency, n (\%) & $80(24.8 \%)$ & $3(25.0 \%)$ & $19(19.2 \%)$ & $58(27.4 \%)$ & 0.299 \\
\hline Median GFD duration in months (IQR) & $72.0(36.0-142.0)$ & $95.5(36.0-196.0)$ & $60.0(36.0-135.0)$ & $72.0(34.5-143.5)$ & 0.713 \\
\hline
\end{tabular}

*Significant at the 0.05 probability level; ${ }^{\dagger}$ Fisher's Exact test used since $>20 \%$ of cells had an expected count below 5 ; ${ }^{*}$ For ethnicity, $\mathrm{n} / \mathrm{N}$ (\%) represents the number of patients in each group with White/Caucasian ethnicity as a fraction of those for whom ethnicity data was available; VA: villous atrophy; D1: duodenal bulb; D2: second part of the duodenum. 


\begin{tabular}{|c|c|c|c|c|c|c|}
\hline \multirow[t]{3}{*}{ Characteristic } & \multicolumn{4}{|c|}{ VA confined to D1 $(n=12)$} & \multirow{2}{*}{\multicolumn{2}{|c|}{$\begin{array}{l}\text { Other VA patterns }(\mathrm{n}=99) \\
\text { Compared with no VA }(\mathrm{n}=212)\end{array}$}} \\
\hline & \multicolumn{2}{|c|}{$\begin{array}{l}\text { Compared with no VA } \\
(\mathrm{n}=212)\end{array}$} & \multicolumn{2}{|c|}{$\begin{array}{l}\text { Compared with other VA } \\
\text { patterns }(\mathrm{n}=99)\end{array}$} & & \\
\hline & AOR & $\mathrm{p}$ & AOR & $\mathrm{p}$ & AOR & $\mathrm{p}$ \\
\hline Age (years) & $1.02(0.98-1.07)$ & 0.29 & $1.03(0.98-1.08)$ & 0.28 & $1.01(1.00-1.03)$ & 0.17 \\
\hline Female gender & $0.44(0.13-1.55)$ & 0.20 & $0.29(0.06-1.43)$ & 0.13 & $1.15(0.65-2.04)$ & 0.63 \\
\hline Constipation & $0.54(0.05-5.60)$ & 0.60 & $0.61(0.03-13.46)$ & 0.75 & $0.82(0.37-1.82)$ & 0.63 \\
\hline Diarrhoea & $0.94(0.16-5.76)$ & 0.95 & $1.76(0.19-16.32)$ & 0.62 & $1.02(0.47-2.21)$ & 0.96 \\
\hline Alternating bowel habit & $0.82(0.13-5.41)$ & 0.84 & $2.22(0.17-28.80)$ & 0.54 & $0.74(0.33-1.68)$ & 0.48 \\
\hline Flatulence & $1.35(0.30-5.98)$ & 0.70 & $1.23(0.26-5.69)$ & 0.80 & $0.71(0.40-1.25)$ & 0.23 \\
\hline Bloating & $1.63(0.37-.14)$ & 0.51 & $2.47(0.54-11.34)$ & 0.25 & $0.81(0.46-1.42)$ & 0.46 \\
\hline Weight loss & $0.45(0.05-3.89)$ & 0.47 & $0.18(0.02-2.04)$ & 0.17 & $2.14(1.18-3.90)$ & $0.01^{\star}$ \\
\hline Floating stools & $0.65(0.13-3.38)$ & 0.61 & $0.30(0.04-2.31)$ & 0.25 & $1.46(0.80-2.70)$ & 0.22 \\
\hline Abdominal pain & $1.02(0.11-9.98)$ & 0.99 & $8.84(0.41-91.07)$ & 0.17 & $0.35(0.10-1.27)$ & 0.11 \\
\hline Urgency & $1.00(0.22-4.61)$ & 1.00 & $2.36(0.29-19.47)$ & 0.43 & $0.66(0.34-1.28)$ & 0.22 \\
\hline Low energy & $0.51(0.13-2.03)$ & 0.34 & $0.45(0.10-2.13)$ & 0.32 & $0.78(0.44-1.38)$ & 0.39 \\
\hline GFD duration (months) & $1.00(0.99-1.00)$ & 0.57 & $1.00(1.00-1.01)$ & 0.50 & $1.00(0.99-1.00)$ & 0.91 \\
\hline
\end{tabular}

${ }^{*}$ Significant at the 0.05 probability level; AOR: adjusted odds ratio; D1: duodenal bulb; GFD: gluten free diet; VA: villous atrophy.

All non-invasive adherence markers showed correlation to histology $(\mathrm{p}<0.0001)$ except the CDAT ( $\mathrm{p}=0.309)$ (Table IV). Table $\mathrm{V}$ outlines the diagnostic performance and AUC on ROC analysis for the non-invasive adherence markers.

\section{DISCUSSION}

To our knowledge, this is the largest study evaluating the increased yield of additional D1 biopsies in detecting persisting VA and potential ongoing gluten exposure in CD patients. We report a significant increase of $10.4 \%(\mathrm{p}<0.0001)$ in the detection rate of persisting VA by taking an additional D1 biopsy. From the patients with lesion discrepancy, 50\% had more severe lesions in the D1. Furthermore, out of the 15 patients with varying degrees of VA between D1 and D2, more severe VA was present in the D1 in $86.7 \%$. Although based on a small sample, this supports the theory of distal to proximal small bowel healing after gluten withdrawal $[33,37,38]$. This pattern may be due to higher gluten load in the proximal small bowel [30], resulting in greater and more long-lasting bulbar damage compared to distally where the gluten load is reduced $[37,38]$. Alternatively, D1 lesions may be caused by ingestion of trace amounts of gluten [33] only sufficient to cause proximal small bowel damage. Duodenal bulb biopsies may prove invaluable when assessing GFD adherence by allowing detection of persisting VA where exposure to gluten is greatest. However, notably, the presence of Brunner's glands and increased risk of gastric metaplasia in the duodenal bulb may result in alteration of bulb villi for reasons unrelated to active CD [39].

This study is among the first to investigate whether patients with persisting VA confined to the duodenal bulb are demographically or phenotypically different to other patients. From our sample of patients, only 14 patients were identified as having persisting VA confined to the bulb. In order to ascertain demographic and clinical differences, a larger sample size of these patients should be sought. Patients with more extensive persisting VA were more likely to present with ongoing weight loss than patients without persisting VA [adjusted odds ratio (AOR) 2.14] . Although correction for multiple testing was not made, the AOR of 2.14 is large enough to assume clinical importance.

The lack of association between the majority of clinical features and pattern of persisting VA may be due to the high prevalence of persisting symptoms even among patients without persisting VA. The most prevalent symptoms among

Table IV. Association between non-invasive markers of adherence and VA

\begin{tabular}{lcccc}
\hline Non-invasive marker & $\begin{array}{c}\text { Total cohort } \\
(\mathrm{n}=201)\end{array}$ & $\begin{array}{c}\text { With persisting } \\
\text { VA }(\mathrm{n}=63)\end{array}$ & $\begin{array}{c}\text { Without persisting } \\
\text { VA }(\mathrm{n}=138)\end{array}$ & p-value \\
\hline Positive Biagi score ${ }^{\dagger}, \mathrm{n}(\%)$ & $18(9.0 \%)$ & $13(20.6 \%)$ & $5(3.6 \%)$ & $<0.0001^{*}$ \\
Positive $\mathrm{CDAT}^{\dagger}, \mathrm{n}(\%)$ & $101(50.2 \%)$ & $35(55.6 \%)$ & $66(47.8 \%)$ & 0.309 \\
Positive IgA-EMA & $29(14.4 \%)$ & $24(38.1 \%)$ & $5(3.6 \%)$ & $<0.0001^{\star}$ \\
Positive IgA-tTG & $33(16.4 \%)$ & $25(39.7 \%)$ & $8(5.8 \%)$ & $<0.0001^{*}$ \\
\hline
\end{tabular}

* Significant at the 0.05 probability level; ${ }^{\dagger} \mathrm{A}$ "positive" result on these non-invasive markers indicates poor adherence; CDAT: Coeliac Dietary Adherence Tool; EMA: anti-endomysium antibodies; tTG: anti-tissue transglutaminase antibodies; VA: villous atrophy. 
Table V. Diagnostic performance of non-invasive markers in the detection of persisting VA when measured against duodenal histology

\begin{tabular}{lccccc}
\hline $\begin{array}{l}\text { Non- invasive } \\
\text { marker }\end{array}$ & Sensitivity \% (CI) & Specificity \% (CI) & PPV \% (CI) & NPV \% (CI) & $\begin{array}{c}\text { ROC analysis } \\
\text { AUC (CI) }\end{array}$ \\
\hline Biagi & $20.6(11.5-32.7)$ & $96.4(91.8-98.8)$ & $72.2(49.2-87.5)$ & $72.7(70.0-75.2)$ & $0.59(0.50-0.67)$ \\
CDAT & $55.6(42.5-68.1)$ & $52.2(43.5-60.7)$ & $34.7(28.6-41.3)$ & $72.0(65.2-78.0)$ & $0.54(0.45-0.63)$ \\
IgA-EMA & $38.1(26.2-51.2)$ & $96.4(91.8-98.8)$ & $82.8(65.8-92.3)$ & $77.3(73.7-80.6)$ & $0.67(0.59-0.76)$ \\
IgA-tTG & $39.7(27.6-52.8)$ & $94.2(88.9-97.5)$ & $75.8(59.9-86.7)$ & $77.4(73.6-80.8)$ & $0.67(0.57-0.76)$ \\
\hline
\end{tabular}

AUC: area under the curve; CDAT: Coeliac Dietary Adherence Tool; CI: confidence interval; EMA: anti-endomysium antibodies; NPV: negative predictive value; PPV: positive predictive value; ROC: receiver operating characteristic; tTG: anti-tissue transglutaminase antibodies; VA: villous atrophy.

patients without VA were fatigue $(73.1 \%)$, bloating $(56.1 \%)$, and flatulence (46.7\%), which could be due to other conditions associated with $\mathrm{CD}$, such as irritable bowel syndrome and small intestinal bacterial overgrowth $[7,14,40]$. These results are in agreement with a large US study concluding that persisting symptoms are not independently associated with persisting histological damage in CD patients [41].

Progression of mucosal healing against time elapsed since CD diagnosis is a vital concept, since this denotes optimal timing of repeat biopsies [14]. Often studies reporting rate of mucosal healing demonstrate a trend for higher rates of mucosal healing as time from diagnosis increases [19, 21]. Previous studies have demonstrated that many patients can be identified as 'slow responders' [19, 21, 42, 43]. The cause of delayed healing in many CD patients is debated. Owing to the difficulty of GFD adherence, the learning process involved in achieving adequate adherence is a proposed reason [20]. Another explanation could be gradual development of gluten tolerance $[44,45]$. A recent large prospective study reported that among non-adherent patients, 57\% achieved Marsh 0 histology and $66 \%$ had only non-atrophic lesions [44]. Thus, among CD patients sporadically ingesting gluten-containing foods, a degree of tolerance towards gluten can be achieved [44]. Delayed mucosal healing among CD patients may occur if development of tolerance takes time [46]. The lack of mucosal healing in some individuals could, perhaps, be due to gluten super-sensitivity, when individuals react to quantities of gluten at a level that most CD patients are tolerant to [14, 47]. In these patients urine gluten immunogenic peptides can detect levels of gluten exposure not currently detected by serology or adherence questionnaires [48]. This retrospective observational study design is not without limitations, with very similar limitations described in other studies investigating rate of mucosal healing $[19,49]$. Biopsies provide a snapshot of mucosal appearance at the time of sampling, making it impossible to determine whether mucosal healing occurred at an earlier time.

The accuracy of non-invasive markers of adherence in this study reflects the findings of previous studies. IgA-tTG and IgA-EMA serology, and the Biagi score showed very low sensitivities when predicting persisting VA, comparable to results of other studies $[25,26]$. A major strength of this study is that it is the first to compare the performance of the CDAT against duodenal histology. Positive CDAT scores were found in $55.6 \%$ of patients with persisting VA and $47.8 \%$ of those without persisting VA $(p=0.309)$. Interestingly, the CDAT was the only non-invasive marker that failed to demonstrate a significant correlation to duodenal histology. When measured against duodenal histology, the CDAT had a sensitivity of $55.6 \%$ and specificity of $52.2 \%$. On ROC analysis the CDAT performed worst out of the adherence markers investigated, producing an AUC of 0.54 (CI: $0.45-0.63$ ). CDAT's poor performance on ROC analysis is due to its significantly lower specificity and PPV than all of the other non-invasive markers $(\mathrm{p}<0.05)$.

The low specificity of the CDAT is explained by the large number of false positive results generated by the questionnaire. This is most likely due to a combination of inclusion of symptom assessment in the questionnaire, and a low cut-off value defining poor adherence. Firstly, the relationship between symptomology and GFD adherence is ambiguous [50-53]. As reiterated in this study, persisting symptoms can occur in patients without persisting VA. The symptoms assessed by the CDAT are low energy levels and headaches within the past four weeks, which both lack exclusivity to patients with active CD. Secondly, the minimum score possible for the CDAT is seven and the threshold for poor adherence is set at scores $\geq 13$ [34]. Thus to be identified as inadequately adherent, patients need to score only six additional points on top of the minimum score. By experiencing symptoms of low energy or headaches either "Most of the time" or a mixture of "Some of the time" and "All of the time", it is possible for patients achieve a score of $\geq 13$ solely on the basis of symptoms. The performance of the CDAT at predicting persisting VA may be improved by increasing the threshold used to define inadequate adherence, or removing/ altering the questions regarding symptomology.

From this study, it is apparent that inclusion of an additional D1 biopsy significantly increases detection of persisting VA. In order to determine the clinical benefit of detecting persisting D1 lesions, future studies should investigate whether patients with persisting VA confined to the D1 are predisposed to haematological deficiencies, osteoporosis, malignancy or other complications in the long-term. Furthermore, the poor performance of the CDAT to detect persisting VA has been displayed for the first time here, confirming that there is not yet a suitable replacement for repeat duodenal biopsies. It appears guidelines should mandate follow-up biopsies in all $\mathrm{CD}$ patients, however further work is required to determine their optimum timing. There remains a need for a sensitive non-invasive marker that can be used repeatedly at follow-up appointments to identify patients likely to have persisting VA and determine need for repeat biopsies. Further studies are 
justified to produce new non-invasive adherence markers, or adapt existing ones, to facilitate the long-term management of CD patients.

\section{CONCLUSIONS}

This study has established the benefit of additional bulbar biopsies during follow-up of CD patients. For the first time, the CDAT questionnaire has been measured against duodenal histology. The poor performance of the CDAT in predicting persisting VA refutes its use for the purpose of selecting patients for repeat endoscopy. This study provides novel results from a large sample of patients referred to our national centre. We suggest that repeat duodenal biopsies, including samples from the duodenal bulb, should be the gold standard for assessing GFD adherence and disease remission in CD. This has the potential to improve and standardise clinical guidelines on the long-term management of $\mathrm{CD}$, including assessment of adherence.

\section{Conflicts of interest: None to declare}

Authors' contributions: S.H.C., A.R., E.M.R.B., M.S.Y.L., L.J.M., and D.S.S. assisted in the planning and conduction of the study. Data collection was completed by S.H.C., A.R., E.M.R.B., L.J.M. and D.S.S. collected the data. Results were interpreted by all investigators. S.H.C. was responsible for the initial manuscript draft. This was reviewed and initially edited by D.S.S., and subsequently reviewed by all authors. All authors approved the final version of the manuscript.

\section{REFERENCES}

1. Ludvigsson JF, Bai JC, Biagi F, et al. Diagnosis and management of adult coeliac disease: guidelines from the British Society of Gastroenterology. Gut 2014;63:1210-1228. doi:10.1136/gutjnl-2013-306578

2. Singh P, Arora A, Strand TA, et al. Global Prevalence of Celiac Disease: Systematic Review and Meta-analysis. Clin Gastroenterol Hepatol 2018;16:823-836.e2. doi: 10.1016/j.cgh.2017.06.037

3. Shah PS, Akbari AM, Vanga AR, et al. Patient perception of treatment burden is high in celiac disease compared with other common conditions. Am J Gastroenterol 2014;109:1304-1311. doi:10.1038/ajg.2014.29

4. Hall NJ, Rubin G, Charnock A. Systematic review: adherence to a glutenfree diet in adult patients with coeliac disease. Aliment Pharmacol Ther 2009;30:315-330. doi:10.1111/j.1365-2036.2009.04053.x

5. Leffler DA, Dennis M, Hyett B, Kelly E, Schuppan D, Kelly CP. Etiologies and predictors of diagnosis in non-responsive celiac disease. Clin Gastroenterol Hepatol 2007;5:445-450. doi:10.1016/j.cgh.2006.12.006

6. Abdulkarim AS, Burgart LJ, See J, Murray JA. Etiology of nonresponsive celiac disease: results of a systematic approach. Am J Gastroenterol 2002;97:2016-2021. doi: 10.1111/j.1572-0241.2002.05917.x.

7. Dewar DH, Donnelly SC, McLaughlin SD, Johnson MW, Ellis HJ, Ciclitira PJ. Celiac disease: management of persistent symptoms in patients on a gluten-free diet. World J Gastroenterol 2012;18:1348-1356. doi:10.3748/wjg.v18.i12.1348

8. Lebwohl B, Granath F, Ekbom A, et al. Mucosal healing and risk for lymphoproliferative malignancy in celiac disease: a population-based cohort study. Ann Intern Med 2013;159:169-175. doi:10.7326/00034819-159-3-201308060-00006
9. Lebwohl B, Michaëlsson K, Green PHR, Ludvigsson JF. Persistent Mucosal Damage and Risk of Fracture in Celiac Disease. J Clin Endocrinol Metab 2014;99:609-616. doi:10.1210/jc.2013-3164

10. Zanchetta MB, Costa AF, Longobardi V, et al. Improved Bone Microarchitecture in Patients With Celiac Disease After 3 Years on a Gluten-Free Diet. Clin Gastroenterol Hepatol 2018;16:774-775. doi:10.1016/j.cgh.2017.09.054

11. Kemppainen TA, Kosma VM, Janatuinen EK, Julkunen RJ, Pikkarainen PH, Uusitupa MI. Nutritional status of newly diagnosed celiac disease patients before and after the institution of a celiac disease diet-association with the grade of mucosal villous atrophy. Am J Clin Nutr 1998;67:482-487. doi:10.1093/ajcn/67.3.482

12. Annibale B, Severi C, Chistolini A, et al. Efficacy of gluten-free diet alone on recovery from iron deficiency anemia in adult celiac patients. Am J Gastroenterol 2001;96:132-137. doi: 10.1111/j.1572-0241.2001.03463.x.

13. Rubio-Tapia A, Hill ID, Kelly CP, Calderwood AH, Murray JA; American College of Gastroenterology. ACG Clinical Guidelines: Diagnosis and Management of Celiac Disease. Am J Gastroenterol 2013;108:656-676. doi:10.1038/ajg.2013.79

14. Baggus EMR, Hadjivassiliou M, Cross S, et al. How to manage adult coeliac disease: perspective from the NHS England Rare Diseases Collaborative Network for Non-Responsive and Refractory Coeliac Disease. Frontline Gastroenterol 2019;11:235-242. doi:10.1136/ flgastro-2019-101191

15. Pinto-Sanchez M, Bai JC. Toward New Paradigms in the Follow Up of Adult Patients With Celiac Disease on a Gluten-Free Diet. Front Nutr 2019;6:153. doi:10.3389/fnut.2019.00153

16. Thanvi BR, Munshi SK, Vijayakumar N, Taub N, Lo TCN. Acceptability of oesophagogastroduodenoscopy without intravenous sedation: patients' versus endoscopist's perception with special reference to older patients. Postgrad Med J 2003;79:650-651. doi:10.1136/pmj.79.937.650

17. Hopper AD, Cross SS, Sanders DS. Patchy villous atrophy in adult patients with suspected gluten-sensitive enteropathy: is a multiple duodenal biopsy strategy appropriate? Endoscopy 2008;40:219-224. doi:10.1055/s-2007-995361

18. Arguelles-Grande C, Tennyson CA, Lewis SK, Green PHR, Bhagat G. Variability in small bowel histopathology reporting between different pathology practice settings: impact on the diagnosis of coeliac disease. J Clin Pathol 2012;65:242-247. doi:10.1136/jclinpath-2011-200372

19. Rubio-Tapia A, Rahim MW, See JA, Lahr BD, Wu TT, Murray JA Mucosal recovery and mortality in adults with celiac disease after treatment with a gluten-free diet. Am J Gastroenterol 2010;105:1412 1420. doi:10.1038/ajg.2010.10

20. Sharkey LM, Corbett G, Currie E, Lee J, Sweeney N, Woodward JM. Optimising delivery of care in coeliac disease - comparison of the benefits of repeat biopsy and serological follow-up. Aliment Pharmacol Thera 2013;38:1278-1291. doi:10.1111/apt.12510

21. Wahab PJ, Meijer JWR, Mulder CJJ. Histologic follow-up of people with celiac disease on a gluten-free diet: slow and incomplete recovery. Am J Clin Pathol 2002;118:459-463. doi:10.1309/EVXT-851X-WHLCRLX9

22. Haere P, Hoie O, Schulz T, Schonhardt I, Raki M, Lundin KE. Longterm mucosal recovery and healing in celiac disease is the rule - not the exception. Scand J Gastroenterol 2016;51:1439-1446. doi:10.1080/ 00365521.2016 .1218540

23. Kurien M, Trott N, Sanders DS. Long-term care for patients with coeliac disease in the UK: a review of the literature and future directions. J Hum Nutr Diet 2016;29:617-623. doi:10.1111/jhn.12379 
24. Biagi F, Vattiato C, Agazzi S, et al. A second duodenal biopsy is necessary in the follow-up of adult coeliac patients. Ann Med 2014;46:430-433. doi:10.3109/07853890.2014.913378

25. Silvester JA, Kurada S, Szwajcer A, Kelly CP, Leffler DA, Duerksen DR. Tests for Serum Transglutaminase and Endomysial Antibodies Do Not Detect Most Patients With Celiac Disease and Persistent Villous Atrophy on Gluten-free Diets: a Meta-analysis. Gastroenterology 2017;153:689701.e1. doi:10.1053/j.gastro.2017.05.015

26. Lau MS, Mooney PD, White WL, et al. The Role of an IgA/IgGDeamidated Gliadin Peptide Point-of-Care Test in Predicting Persistent Villous Atrophy in Patients With Celiac Disease on a Gluten-Free Diet. Am J Gastroenterol 2017;112:1859-1867. doi:10.1038/ajg.2017.357

27. Biagi F, Andrealli A, Bianchi PI, Marchese A, Klersy C, Corazza GR. A gluten- free diet score to evaluate dietary compliance in patients with coeliac disease. Br J Nutr 2009;102:882-887. doi:10.1017/ S0007114509301579

28. Biagi F, Bianchi PI, Marchese A, et al. A score that verifies adherence to a gluten-free diet: a cross-sectional, multicentre validation in real clinical life. Br J Nutr 2012;108:1884-1888. doi:10.1017/ S0007114511007367

29. Galli G, Esposito G, Lahner E, et al. Histological recovery and glutenfree diet adherence: a prospective 1-year follow-up study of adult patients with coeliac disease. Aliment Pharmacol Ther 2014;40:639-647. doi:10.1111/apt.12893

30. Mooney PD, Kurien M, Evans KE, et al. Clinical and Immunologic Features of Ultra-Short Celiac Disease. Gastroenterology 2016;150:11251134. doi:10.1053/j.gastro.2016.01.029

31. McCarty TR, O’Brien CR, Gremida A, Ling C, Rustagi T. Efficacy of duodenal bulb biopsy for diagnosis of celiac disease: a systematic review and meta-analysis. Endosc Int Open 2018;6:E1369-E1378. doi:10.1055/a-0732-5060

32. Evans KE, Aziz I, Cross SS, et al. A prospective study of duodenal bulb biopsy in newly diagnosed and established adult celiac disease. Am J Gastroenterol 2011;106:1837-1842. doi:10.1038/ajg.2011.171

33. Caruso R, Marafini I, Del Vecchio Blanco G, et al. Sampling of proximal and distal duodenal biopsies in the diagnosis and monitoring of celiac disease. Dig Liver Dis 2014;46:323-329. doi:10.1016/j.dld.2013.12.005

34. Leffler DA, Dennis M, Edwards George JB, et al. A simple validated gluten-free diet adherence survey for adults with celiac disease. Clin Gastroenterol Hepatol 2009;7:530-536.E2. doi:10.1016/j. cgh.2008.12.032

35. Johansson K, Norstrom F, Nordyke K, Myleus A. Celiac Dietary Adherence Test simplifies Determining Adherence to a Gluten-free Diet in Swedish Adolescents. J Pediatr Gastroenterol Nutr 2019;69:575-580. doi:10.1097/MPG.0000000000002451

36. Oberhuber G, Granditsch G, Vogelsang H. The histopathology of coeliac disease: time for 11 a standardized report scheme for pathologists. Eur J Gastroenterol Hepatol 1999;11:1185-1194. doi:10.1097/00042737199910000-00019

37. Macdonald WC, Brandborg LL, Flick AL, Trier JS, Rubin CE. Studies of Celiac Sprue. IV. The response of the whole length of the small bowel to a gluten-free diet. Gastroenterology 1964;47:573-589.

38. Murray JA, Rubio-Tapia A, Van Dyke CT, et al. Mucosal atrophy in celiac disease: extent of involvement, correlation with clinical presentation, and response to treatment. Clin Gastroenterol Hepatol 2008;6:186-193. doi:10.1016/j.cgh.2007.10.012

39. Dickson BC, Streutker CJ, Chetty R. Coeliac disease: an update for pathologists. J Clin Pathol 2006;59:1008-1016. doi:10.1136/ jcp.2005.035345

40. Haines ML, Anderson RP, Gibson PR. Systematic review: the evidence base for long-term management of coeliac disease. Aliment Pharmacol Ther 2008;28:1042-1066. doi:10.1111/j.1365-2036.2008.03820.x

41. Mahadev S, Murray JA, Wu TT, et al. Factors associated with villus atrophy in symptomatic coeliac disease patients on a gluten-free diet. Aliment Pharmacol Ther 2017;45:1084-1093. doi:10.1111/apt.13988

42. Lee SK, Lo W, Memeo L, Rotterdam H, Green PHR. Duodenal histology in patients with celiac disease after treatment with a gluten-free diet. Gastrointest Endosc 2003;57:187-191. doi:10.1067/mge.2003.54

43. Lanzini A, Lanzarotto F, Villanacci V, et al. Complete recovery of intestinal mucosa occurs very rarely in adult coeliac patients despite adherence to gluten-free diet. Aliment Pharmacol Ther 2009;29:12991308. doi:10.1111/j.1365-2036.2009.03992.x

44. Elli L, Bascuñán $\mathrm{K}$, di Lernia L, et al. Safety of occasional ingestion of gluten in patients with celiac disease: a real-life study. BMC Med 2020;18:42. doi:10.1186/s12916-020-1511-6

45. Norsa L, Branchi F, Bravo M, et al. Celiac Disease 30 Years After Diagnosis: Struggling With Gluten-free Adherence or Gaining Gluten Tolerance? J Pediatr Gastroenterol Nutr 2018;67:361-366. doi:10.1097/ MPG.0000000000001995

46. Matysiak-Budnik T, Malamut G, de Serre NP, et al. Long-term follow-up of 61 coeliac patients diagnosed in childhood: evolution toward latency is possible on a normal diet. Gut 2007;56:1379-1386. doi:10.1136/ gut.2006.100511

47. Hollon JR, Cureton PA, Martin ML, Puppa ELL, Fasano A. Trace gluten contamination may play a role in mucosal and clinical recovery in a subgroup of diet-adherent non-responsive celiac disease patients. BMC Gastroenterol 2013;13:40. doi:10.1186/1471-230X-13-40

48. Ruiz-Carnicer Á, Garzón-Benavides M, Fombuena B, et al. Negative predictive value of the repeated absence of gluten immunogenic peptides in the urine of treated celiac patients in predicting mucosal healing: new proposals for follow-up in celiac disease. Am J Clin Nutr 2020 Nov 11;112(5):1240-1251. doi:10.1093/ajcn/nqaa188

49. Hutchinson JM, West NP, Robins GG, Howdle PD. Long-term histological follow-up of people with coeliac disease in a UK teaching hospital. QJM 2010;10351:511-517. doi:10.1093/qjmed/hcq076

50. Leffler DA, Edwards-George J, Dennis M, et al. Factors that Influence Adherence to a Gluten-Free Diet in Adults with Celiac Disease. Dig Dis Sci 2008;53:1573-1581. doi:10.1007/s10620-007-0055-3

51. Casellas F, Lopez Vivancos J, Malagelada JR. Current epidemiology and accessibility to diet compliance in adult celiac disease. Rev Esp Enferm Dig 2006;98:408-419. doi:10.4321/s1130-01082006000600002

52. Viljamaa M, Collin P, Huhtala H, Sievänen H, Mäki M, Kaukinen K. Is coeliac disease screening in risk groups justified? A fourteen-year follow-up with special focus on compliance and quality of life. Aliment Pharmacol Ther 2005;22:317-324. doi:10.1111/j.1365-2036.2005.02574.x

53. Kurppa K, Lauronen O, Collin P, et al. Factors associated with dietary adherence in celiac disease: a nationwide study. Digestion 2012;86:309314. doi:10.1159/000341416 